\title{
Evaluation of marginal adaptation in three-unit frameworks fabricated with conventional and powder-free digital impression techniques
}

\author{
Hasan Kocaağaoğlu' ${ }^{1}$, Haydar Albayrak², Sezgi Cinel Sahin ${ }^{3 *}$, Ayşegül Güleryüz Gürbulak ${ }^{2}$ \\ ${ }^{1}$ Private Practice, Calhan Dental Clinic, Denizli, Turkey \\ ${ }^{2}$ Department of Prosthodontics, Faculty of Dentistry, Erciyes University, Kayseri, Turkey \\ ${ }^{3}$ Department of Prosthodontics, Faculty of Dentistry, Pamukkale University, Pamukkale, Turkey
}

\begin{abstract}
PURPOSE. The purpose of this in vitro study was to evaluate the marginal misfits of three-unit frameworks fabricated with conventional and digital impressions techniques. MATERIALS AND METHODS. Thirty brass canine and second premolar abutment preparations were fabricated by using a computer numerical control machine and were randomly divided into 3 groups $(n=10)$ as follows: conventional impression group (Group $\mathrm{Ci}$ ), Cerec Omnicam (Group Cdi), and 3shape TRIOS-3 (Group Tdi) digital impression groups. The laser-sintered metal frameworks were designed and fabricated with conventional and digital impressions. The marginal adaptation was assessed with a stereomicroscope at $\times 30$ magnification. The data were analyzed with 1-way analysis of variances (ANOVAs) and the independent simple $t$ tests. RESULTS. A statistically significant difference was found between the frameworks fabricated by conventional methods and those fabricated by digital impression methods. Multiple comparison results revealed that the frameworks in Group Ci (average, $98.8 \pm$ $16.43 \mu \mathrm{m}$; canine, $93.59 \pm 16.82 \mu \mathrm{m}$; premolar, $104.10 \pm 15.02 \mu \mathrm{m}$ ) had larger marginal misfit values than those in Group Cdi (average, $63.78 \pm 14.05 \mu \mathrm{m}$; canine, $62.73 \pm 13.71 \mu \mathrm{m}$; premolar, $64.84 \pm 15.06 \mu \mathrm{m}$ ) and Group Tdi (average, $65.14 \pm 18.05 \mu \mathrm{m}$; canine, $70.64 \pm 19.02 \mu \mathrm{m}$; premolar, $59.64 \pm 16.10 \mu \mathrm{m})(P=.000$ for average; $P=.001$ for canine; $P<.001$ for premolar). No statistical difference was found between the marginal misfits of canine and premolar abutment teeth within the same groups $(P>.05)$. CONCLUSION. The three-unit frameworks fabricated with digital impression techniques showed better marginal fit compared to conventional impression techniques. All marginal misfit values were clinically acceptable. [J Adv Prosthodont 2019;11:262-70]
\end{abstract}

KEYWORDS: Marginal misfit; Three-unit framework; Digital impression; Conventional impression; Computeraided design / Computer-aided manufacturing

\section{INTRODUCTION}

Metal-ceramic restorations have been successfully used in fixed partial dentures (FPDs) for many years because of

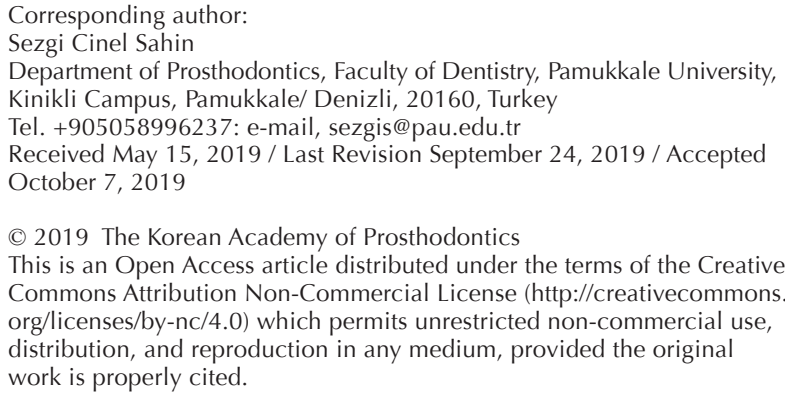

their favorable long-term clinical performance. ${ }^{1}$ Accurate impression making is one of the most important stages in fabricating FPDs, ${ }^{2}$ and insufficiently detailed impressions may result in incompatible marginal adaptation of the restorations. ${ }^{3}$ Conventional impression techniques require high technical skills, and restorations may deform during the fabrication stages in the laboratory. ${ }^{4,5}$ Factors such as the change in ambient temperature, the length of time between impression and casting, the type and/or quality of the cast material, the storage conditions of the impression and cast material, surface wettability of the impression material, and disinfection procedures are technical issues of the conventional impression method, and these factors directly affect the compatibility of the restorations. Fabrication processes such as the application of the die spacer as well as laboratory steps for prosthesis production such as waxing, investing, 
casting or pressing process can result in dimensional error and affect the fit of the definitive restoration. Contrary to these disadvantages, the conventional impression technique is inexpensive than the digital technique. ${ }^{6}$

Digital impression systems were developed as an alternative to conventional impression systems. ${ }^{7-9}$ However, scanning with powder, low-resolution, and insufficient computing power caused restorations with unacceptable values of marginal misfit. ${ }^{10}$ The CEREC 1 system (Sirona Dental Systems GmbH, Bensheim, Germany) was the first commercially available intraoral impression system and was developed in 1987. ${ }^{11,12}$ With the development of fabrication technology and engineering, highly accurate scanners, more advanced software, and several digital intraoral impression systems have become available. ${ }^{11-14}$ With these systems, crowns or FPDs can be fabricated on the images of the prepared teeth captured by the intraoral scanning device. ${ }^{11,12,15}$ As a consequence, several problems of conventional impression making can been eliminated. ${ }^{11,16}$ Nowadays, The CEREC Omnicam (DentsplySirona, Bensheim, Germany), ${ }^{11}$ the Lava chair side oral scanner (Lava COS; 3M ESPE, St. Paul, MN, USA), ${ }^{9,11,17}$ iTero (Align Technology, Inc., San Jose, CA, USA), ${ }^{2}$ Trios3 (3Shape A/S, Copenhagen, Denmark), ${ }^{9,18}$ and E4D PlanScan (d4d, Planmeca, Richardson, TX, USA) ${ }^{19}$ systems are frequently used to fabricate dental prostheses.

The Trios3 intraoral scanning system (3Shape A/S, Copenhagen, Denmark) is the first generation scanner and the system works on the principle of ultrafast optical section and confocal microscopy. ${ }^{20}$ It uses a quick scanning speed and captures up to 3000 figures per second. As the effect of relative movement between the scanning probe and teeth is reduced, contrast spraying is unnecessary. ${ }^{18}$ The Cerec Omnicam (DentsplySirona, Bensheim, Germany) works on the principle of active triangulation. It uses a white light to capture the image and captures data continually in color, again without the need for contrast spraying. ${ }^{17}$

The digital impression is a noninvasive technique, which involves the use of an intraoral scanner of small dimensions that does not create discomfort for the patient. The scanner records a series of snapshots of the oral cavity of the patient, which are transferred onto a computer where they will be processed and a virtual model will be obtained. ${ }^{12}$ In this way, all the requirements expected from the restoration can be examined from the data obtained and the desired restoration planning can be realized. This technique has significant advantages in eliminating operator dependent variability, reducing impression time and treatment cost, and improving patient compliance for rehabilitation over conventional impression technique. ${ }^{21}$ Contrary to these superior features, the digital impression technique may show particular shortcomings in transferring subgingival margins to the system. In this technique, the full reflection of the gingival margin to the system is possible only by providing ideal isolation. Today, retraction cords and rubber dams are used for this purpose. Otherwise, it is inevitable that the produced restorations will fail clinically. ${ }^{12}$

Several factors affect the success of dental restorations ${ }^{22}$ and it has been reported that the incidence of biological complications is greater than mechanical complications in metal-ceramic restorations. ${ }^{23-29}$ Accurate adaptation seems to be one of the most important factors for the longevity of a restoration..$^{25-27}$ The restoration boundary should be perfectly adapted to the finish line of the prepared tooth. In practice, it is impossible to achieve perfect adaptation. The misfit of a complete coverage restoration can cause luting agent dissolution, leakage, the risk of secondary caries, ${ }^{28}$ hypersensitivities, and periodontal disease. ${ }^{13}$

Numerous studies evaluating the marginal and/or internal adaptation of single-unit dental restorations fabricated with digital impression systems are available in the literature,,$^{2,13-16,30}$ but a small number of studies are about marginal misfit of three-unit metal frameworks fabricated with different impression techniques. ${ }^{18,29}$ The number of studies evaluating the marginal misfit of three-unit frameworks fabricated with different impression techniques is small and the results of the studies are incompatible. ${ }^{18,29,31}$ In some studies, it was reported that there is inconsistency between the marginal misfits of different abutment teeth in the frameworks fabricated with the same impression technique. ${ }^{23,31,32}$ However, incompatible data are insufficient to reach consensus on this issue. ${ }^{23,32}$ Because of these shortcomings, the primary purpose of this in vitro study was to evaluate the marginal misfit of three-unit frameworks fabricated with two digital and one conventional impression technique. The secondary purpose was to evaluate whether the marginal misfits differentiate according to the type of abutment teeth supporting the same three-unit framework specimens. The primary null hypothesis was that there was no difference between digital and conventional impression techniques on the marginal misfit of three-unit laser-sintered frameworks. The secondary null hypothesis was that there was no difference between the marginal misfit values of different abutment teeth supporting the same framework.

\section{MATERIALS AND METHODS}

Artificial left maxillary canine and second premolar teeth (ANKA-4 Z, Frasaco GmbH, Tettnang, Germany) were used for fabrication of master dies. The abutment teeth were prepared as follows: 6 degrees of convergence angle, anatomic occlusal preparation of approximately $2 \mathrm{~mm}$, axial preparation of approximately 1 to $1.5 \mathrm{~mm}$, and a shoulder circumferential finish line of 1.0 $\mathrm{mm}$ in depth. The teeth were prepared by using a paralellometer (Paraskop, Hebst GmbH \& Co., Bremen, Germany) to eliminate any undercuts. Thirty canine and 30 second premolar brass abutments were duplicated (Sarbak Metal, Sarbak Co., Istanbul, Turkey) from the prepared master teeth by using a computer numerical control (CNC) machine YM 64DV jig borer (Victor, Taipei, Taiwan). ${ }^{33}$

According to power analysis (95\% power and $P<.05)$, thirty study specimens were obtained by assembling these brass abutments (Fig. 1) and they were divided into 3 equal groups $(n=10)$ for fabrication of cast dies with conventional and digital impression techniques. ${ }^{30}$ 
In Group Ci, the frameworks were fabricated with conventional impression techniques, in which two-stage impressions were made with a polyvinyl siloxane (PVS) impression material (Variotime Easy Putty and Light Flow, Heraeus Kulzer GmbH, New York, NY, USA) and a custom tray. The conventional two-stage impression process was performed by applying finger pressure for 5 minutes at room temperature on the custom tray and the impression was taken for each study specimens in this group by the same experienced operator each time. After finishing the impression process, the same operator examined the quality of all impression about the tears and voids and connection between the custom tray and impression material. When an impression was assessed as having a critical defect, the impression was retaken. ${ }^{3,21,32}$ After the impressions had been removed from the abutments, they were disinfected for 10 minutes (Impresept, 3M ESPE, St. Paul, MN, USA). Type IV dental stone was poured into the impressions (Fujirock EP, GC Corp., Tokyo,

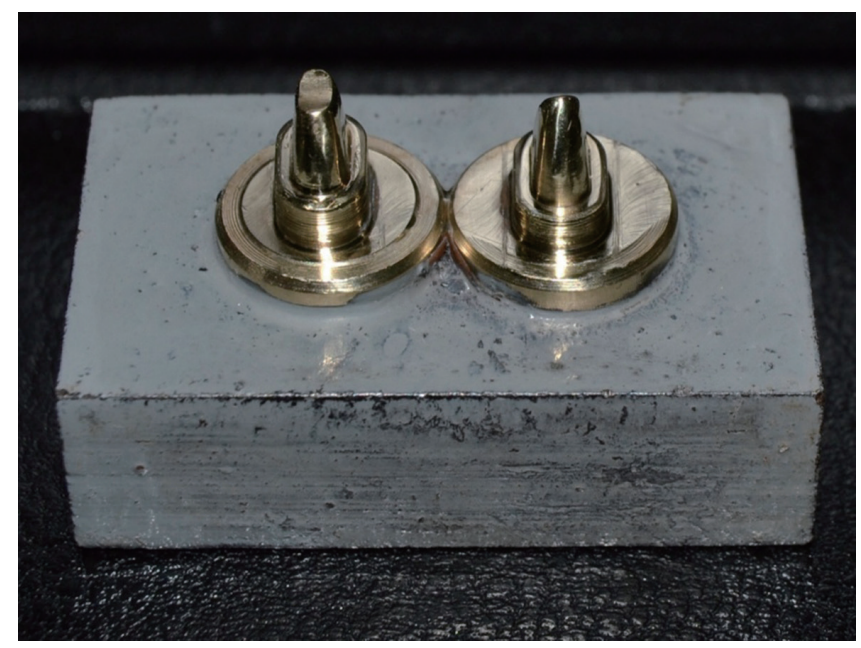

Fig. 1. Brass study dies.

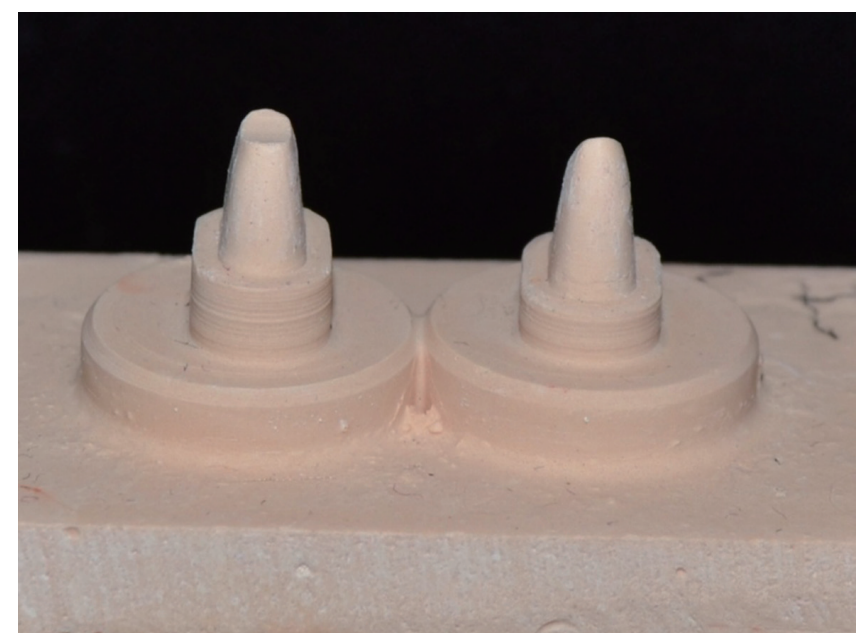

Fig. 2. Cast die from the Group Ci.
Japan) according to the manufacturer's instructions to obtain casts. Ten cast die models were obtained from each of the Group Ci specimens and then sent to the dental laboratory for the fabrication of the three-unit LS frameworks (Fig. 2).

In Groups Cdi and Tdi, the frameworks were fabricated with digital impression techniques, in which study specimens were scanned with a CEREC Omnicam (DentsplySirona, Bensheim, Germany) and a 3 shape TRIOS-3 (3Shape A/S, Copenhagen, Denmark) intraoral scanning systems, respectively (Fig. 3 and Fig. 4).

The digital scanning was performed by the same experienced operator (H.K.) and the scan was continuously assessed during the scanning procedure. If a critical defect was observed, the scan was corrected by rescanning the flawed area. Specific scanning was performed for each study specimens in Group Cdi and Tdi. In total, 10 scan files were obtained for each digital measurement technique. After the scan was finished successfully, the scan files were converted

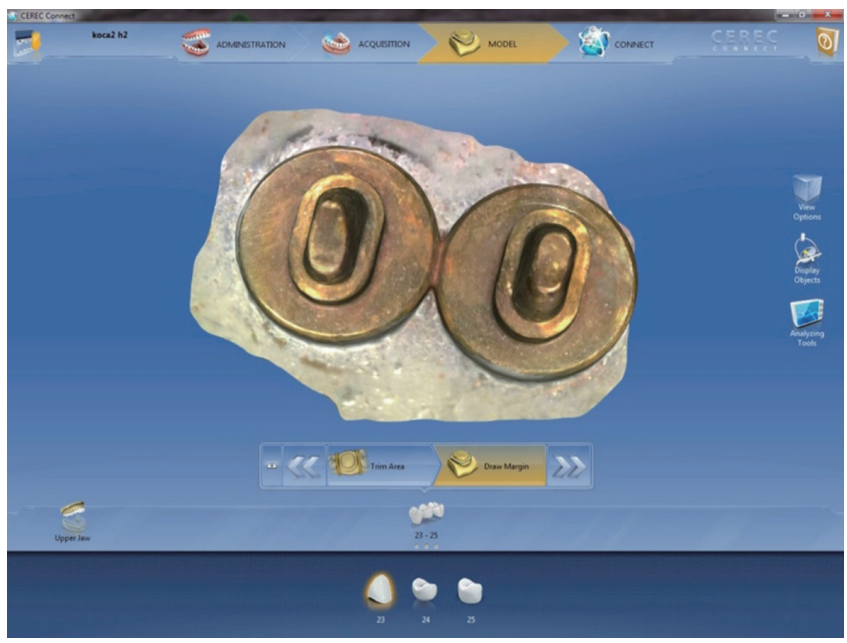

Fig. 3. Digital die from the Group Cdi.

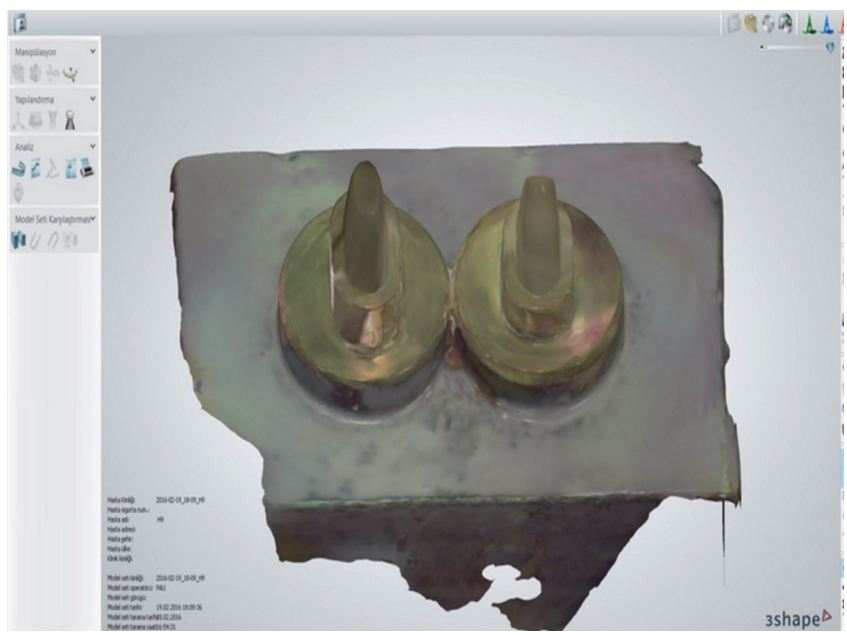

Fig. 4. Digital die from the Group Tdi. 
to STL image format and then sent to a dental laboratory for the fabrication of the there-unit LS frameworks.

The frameworks were designed by an experienced dental technician with a CAD program (Dwos, Dental Wings, Montreal, Canada) with a $0.5 \mathrm{~mm}$ thick abutment framework, a $3 \mathrm{~mm}$ pontic width, a $3 \mathrm{~mm}$ connector height, a 3 $\mathrm{mm}$ connector width, and a $20 \mu \mathrm{m}$ cement space $(0.5 \mathrm{~mm}$ from the margin) for the abutment of the working cast. The frameworks were then fabricated with a prototyping technology. With this technology, a high precision (EOSINT M270, EOS GmbH, Krailling, Munich, Germany), highenergy laser (yb-fiber laser of approximately $200 \mathrm{~W}$ with compressed air of $7000 \mathrm{hPa}$ ) was used to melt a controlled deposition of $20 \mu \mathrm{m}$ thick full dense CoCrMoW alloys made from a commercial alloy powder (EOSINT M EOS CobaltChrome SP2, EOS GmbH). After this sintering procedure was finished, the frameworks were separated from the metallic base and the fabrication phase was terminated (Fig. 5).

According to the manufacturer's instructions, ${ }^{34}$ a thermal stress relieving process was performed and then all frameworks were evaluated for internal surface defects that could prevent their complete placement. They were then cleaned ultrasonically (Elmasonic S100H, Elma GmbH\&Co KG, Singen, Germany) in 95\% methyl alcohol for 15 minutes and left to dry. The marginal misfits were measured by using a stereomicroscope (Nikon SMZ 1500, Nikon Corp., Melville, NY, USA) at $30 \times$ magnification on the frameworks. ${ }^{7,26}$ The microscope images were captured by a digital camera (Clemex; Clemex Technologies Inc., Quebec, Canada) that was connected to the microscope (Fig. 6) and transferred to a computer.

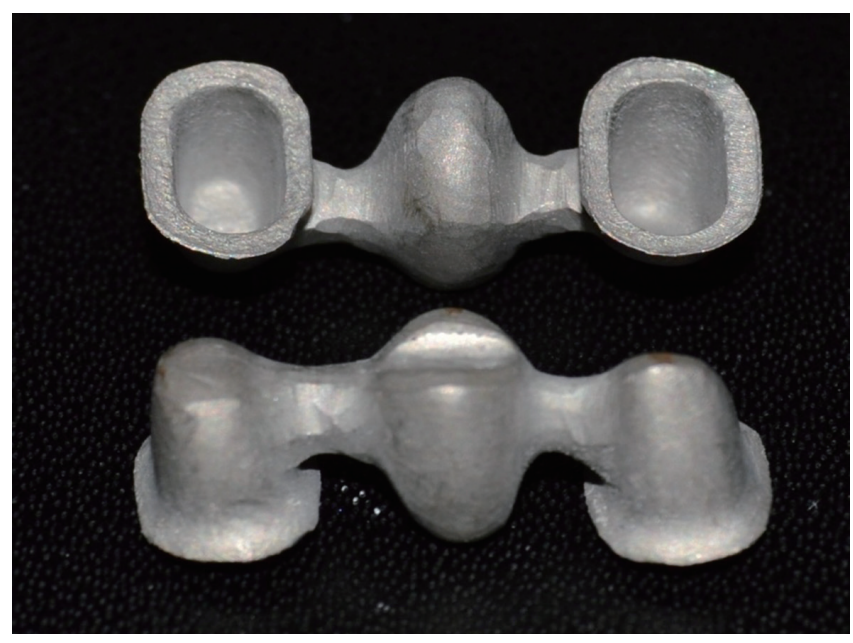

Fig. 5. View of fabricated frameworks.
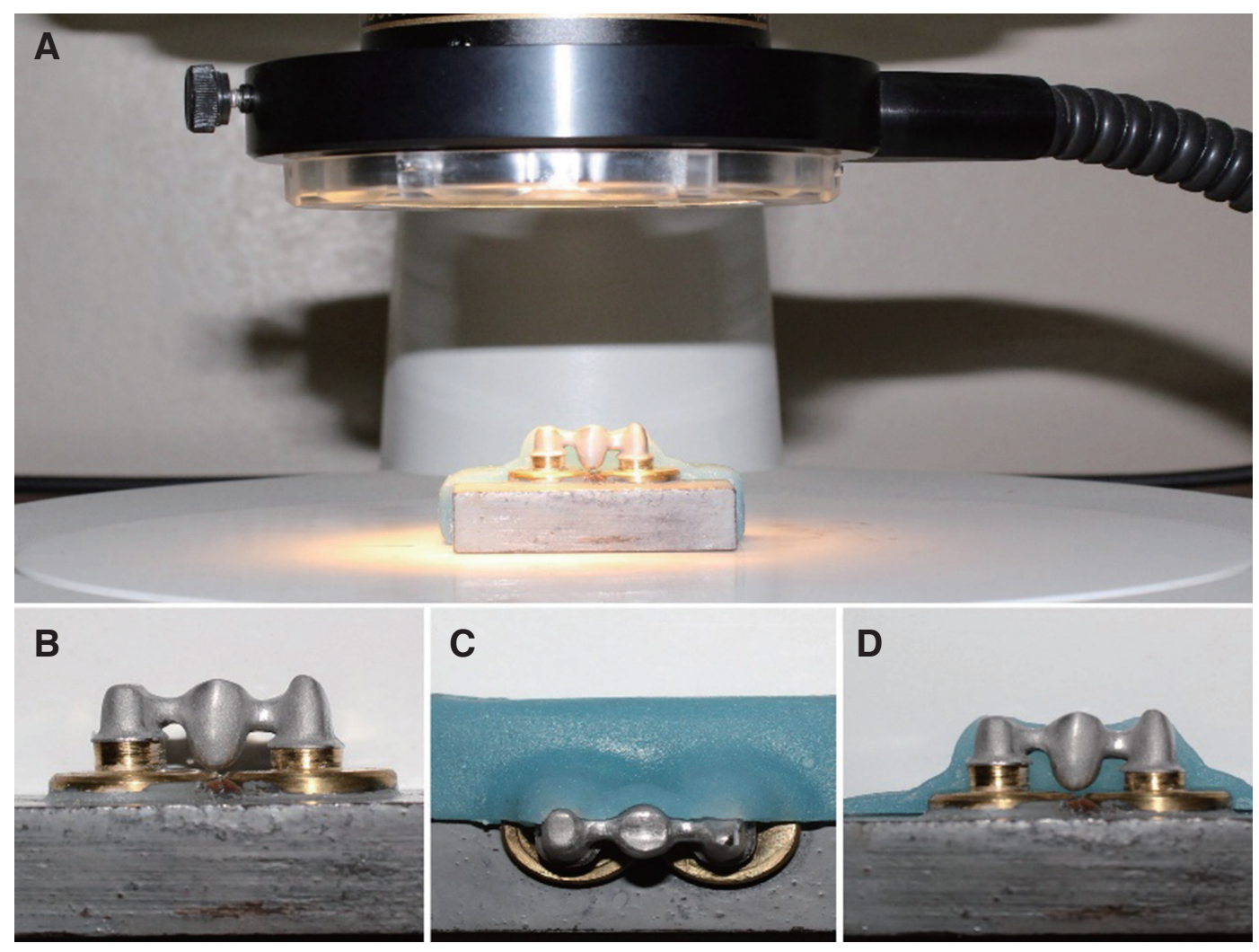

Fig. 6. Marginal fit measurement using stereomicroscope: (A) view of the framework and brass die under the stereomicroscope, (B) framework with brass die, (C) acrylic fixative in occlusal view, (D) acrylic fixative in buccal view. 


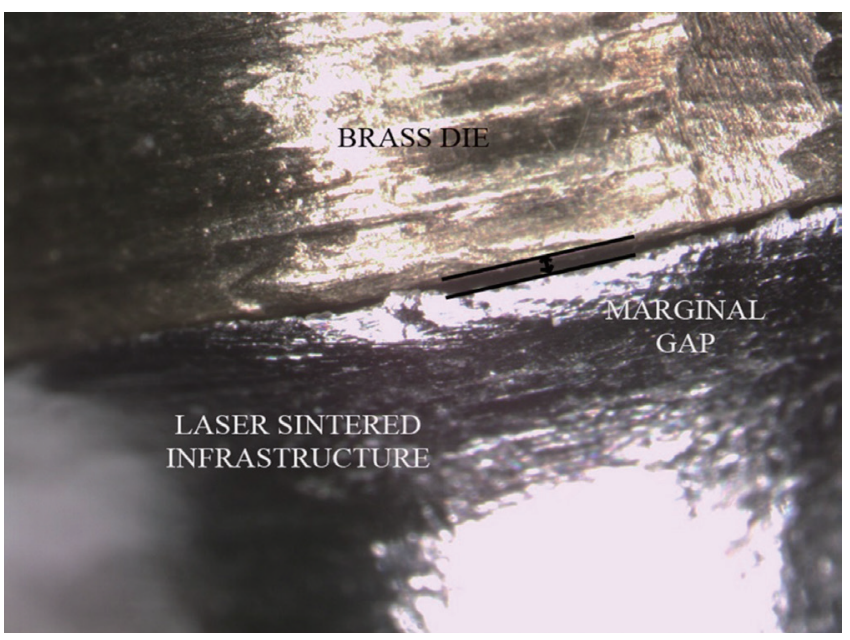

Fig. 7. Stereomicroscope image of marginal fit at $30 \times$ magnification.

Measurements were made for each surface (buccal, mesial, distal, and palatal) of each abutment (canine and premolar) from the edge of the shoulder finish line of the dies to the inferior edge of the frameworks (Fig. 7). ${ }^{35,36}$

Marginal discrepancy measurements were made four times from each side of each abutment using a computer program (Vision Lite, Clemex Technologies Inc., Quebec, Canada). ${ }^{36}$ In total, 480 measurements were made for each abutment. Average values of these measurements were calculated for each abutment separately and the average total marginal misfit values of frameworks were recorded.

The recorded misfit data of each abutment and total marginal misfit data were subjected to the KolmogorovSmirnov test to examine whether the data were normally distributed $(\alpha=.05)$. One-way ANOVAs was performed because the data in all groups were consistent with normal distribution. The HSD Tukey post hoc tests were applied to evaluate marginal misfit values among each abutment groups. Possible marginal agreement differences between abutment teeth were analyzed by independent simple $t$ tests $(\alpha=.05)$. Statistical analyses were performed by using a software program with a $95 \%$ confidence interval (SPSS 20.0 V, SPSS Inc., Chicago, IL, USA).

\section{RESULTS}

Table 1 shows one-way ANOVA values of canine and premolar teeth and total average values. Table 2 shows mean and standard deviation (SD) values of the abutment teeth and total average marginal misfits values. As shown in Table 2 , statistically significant differences were found between the framework groups produced with conventional and digital measurements in terms of marginal discrepancy $(P<$ .001). According to the Tukey multiple comparison test, Group Ci revealed larger marginal misfits than those of Group Cdi and Group Tdi in both abutment teeth $(P=$ .000 for average; $P=.001$ for canine; $P<.001$ for premolar). However, no statistically significant difference was found between Group Tdi and Group Cdi in either abutment tooth $(P>.05)$ (Table 2).

The results of the t-test examining the possible marginal discrepancy differences between the abutment teeth supporting the same independent framework specimens showed that there was no statistical difference between the abutment teeth in terms of marginal discrepancy $(P>.05)$ (Table 3).

\section{DISCUSSION}

In this study, the marginal misfit of three-unit laser-sintered (LS) frameworks fabricated by different digital impression techniques was compared with that of the frameworks fabricated by the conventional impression technique. According to the data obtained, the primary null hypothesis that there were no differences between digital and conventional impression techniques on the marginal misfit of three-unit laser-sintered metal frameworks was rejected. In the study, the total mean marginal misfit values of Group Cdi and Group Tdi specimens were found to be significantly smaller than Group $\mathrm{Ci}(P=.000)$. In addition, the marginal misfits in Group Cdi and in Group Tdi were also significantly

Table 1. One-way ANOVAs of canine and premolar teeth and total average values

\begin{tabular}{|c|c|c|c|c|c|c|}
\hline & & Sum of squares & df & Mean square & $\mathrm{F}$ & Sig. \\
\hline \multirow[t]{3}{*}{ Canine } & Between Groups & 5140.250 & 2 & 2570.125 & 9.258 & .001 \\
\hline & Within Groups & 7495.695 & 27 & 277.618 & & \\
\hline & Total & 12635.945 & 29 & & & \\
\hline \multirow[t]{3}{*}{ Premolar } & Between Groups & 11818.300 & 2 & 5909.150 & 24.917 & $<.001$ \\
\hline & Within Groups & 6403.194 & 27 & 237.155 & & \\
\hline & Total & 18221.494 & 29 & & & \\
\hline Total & Between Groups & 15783.600 & 2 & 7891.800 & 29.833 & .000 \\
\hline \multirow[t]{2}{*}{ (Canine+Premolar) } & Within Groups & 15078.214 & 57 & 264.530 & & \\
\hline & Total & 30861.814 & 59 & & & \\
\hline
\end{tabular}


Table 2. Mean and standard deviations $( \pm \mathrm{SD})$ values of the abutment teeth and total marginal misfit values $(\mu \mathrm{m})$

\begin{tabular}{|c|c|c|c|c|c|c|c|c|c|c|c|c|c|}
\hline \multirow{2}{*}{$\begin{array}{l}\text { Marginal } \\
\text { Misfits }\end{array}$} & \multirow{2}{*}{$\mathrm{N}$} & \multicolumn{4}{|c|}{ Canine } & \multicolumn{4}{|c|}{ Premolar } & \multicolumn{4}{|c|}{ Total (Canine + Premolar) } \\
\hline & & Group Ci & Group Cdi & Group Tdi & $P$ & Group Ci & Group Cdi & Group Tdi & $P$ & Group Ci & Group Cdi & Group Tdi & $P$ \\
\hline Averaged & 40 & $\begin{array}{c}93.59 \\
(16.82)^{\mathrm{a}}\end{array}$ & $\begin{array}{c}62.73 \\
(13.71)^{b}\end{array}$ & $\begin{array}{c}70.64 \\
(19.02)^{b}\end{array}$ & .001 & $\begin{array}{c}104.10 \\
(15.02)^{a}\end{array}$ & $\begin{array}{c}64.84 \\
(15.06)^{b}\end{array}$ & $\begin{array}{c}59.64 \\
(16.10)^{b}\end{array}$ & $<.001$ & $\begin{array}{c}98.8 \\
(16.43)^{a}\end{array}$ & $\begin{array}{c}63.78 \\
(14.05)^{b}\end{array}$ & $\begin{array}{c}65.14 \\
(18.05)^{b}\end{array}$ & .000 \\
\hline Mesial & 10 & $\begin{array}{l}84.68 \\
(26.48)\end{array}$ & $\begin{array}{l}48.78 \\
(20.45)\end{array}$ & $\begin{array}{l}55.47 \\
(22.82)\end{array}$ & & $\begin{array}{l}106.34 \\
(11.47)\end{array}$ & $\begin{array}{c}66.77 \\
(17.46)\end{array}$ & $\begin{array}{l}63.08 \\
(26.29)\end{array}$ & & $\begin{array}{l}95.51 \\
(22.18)\end{array}$ & $\begin{array}{l}57.77 \\
(20.67)\end{array}$ & $\begin{array}{l}59.27 \\
(24.27)\end{array}$ & \\
\hline Distal & 10 & $\begin{array}{c}93.19 \\
(10.60)\end{array}$ & $\begin{array}{l}65.45 \\
(20.74)\end{array}$ & $\begin{array}{c}63.32 \\
(13.11)\end{array}$ & & $\begin{array}{l}94.18 \\
(25.04)\end{array}$ & $\begin{array}{l}51.74 \\
(21.70)\end{array}$ & $\begin{array}{l}51.70 \\
(22.60)\end{array}$ & & $\begin{array}{c}93.68 \\
(18.72)\end{array}$ & $\begin{array}{c}58.59 \\
(21.82)\end{array}$ & $\begin{array}{l}57.51 \\
(18.94)\end{array}$ & \\
\hline Buccal & 10 & $\begin{array}{l}92.94 \\
(29.61)\end{array}$ & $\begin{array}{l}60.00 \\
(21.28)\end{array}$ & $\begin{array}{l}85.72 \\
(21.25)\end{array}$ & & $\begin{array}{l}110.10 \\
(23.70)\end{array}$ & $\begin{array}{l}72.00 \\
(21.81)\end{array}$ & $\begin{array}{c}57.37 \\
(15.44)\end{array}$ & & $\begin{array}{l}101.52 \\
(27.54)\end{array}$ & $\begin{array}{l}66.00 \\
(21.85)\end{array}$ & $\begin{array}{l}71.54 \\
(23.20)\end{array}$ & \\
\hline Palatal & 10 & $\begin{array}{l}103.57 \\
(54.34)\end{array}$ & $\begin{array}{c}76.69 \\
(28.82)\end{array}$ & $\begin{array}{l}78.05 \\
(51.36)\end{array}$ & & $\begin{array}{l}105.80 \\
(27.05)\end{array}$ & $\begin{array}{c}68.85 \\
(19.98)\end{array}$ & $\begin{array}{c}66.41 \\
(35.67)\end{array}$ & & $\begin{array}{l}104.68 \\
(41.79)\end{array}$ & $\begin{array}{c}72.77 \\
(24.46)\end{array}$ & $\begin{array}{c}72.23 \\
(43.44)\end{array}$ & \\
\hline
\end{tabular}

*Superscripts refer the statistically significant difference according to the HSD Tukey post-hoc tests $(P<.05)$.

Table 3. Mean $( \pm \mathrm{SD})$ and $P$ values of independent specimens with t test

\begin{tabular}{cccc}
\hline Group & N & Mean (SD) & $P$ \\
\hline Canine & 30 & $75.65(20.87)$ & \\
Premolar & 30 & $76.19(25.06)$ & .928 \\
\hline
\end{tabular}

smaller than those of Group $\mathrm{Ci}$ in either canine or premolar teeth $(P=.001$ and $P<.001$, respectively). In Group $\mathrm{Ci}$, the obtained mean marginal misfit values of frameworks were $93.59 \mu \mathrm{m}( \pm 16.82)$ for canine, $104.10 \mu \mathrm{m}( \pm 15.02)$ for premolar abutment teeth and $98.84 \mu \mathrm{m}( \pm$ 16.43) for the average of both abutments. These results were found to be consistent with similar studies. ${ }^{11,31,35,37}$

Euán et al. ${ }^{7}$ compared single unit zirconia copings fabricated with digital and conventional impression techniques and reported that the restorations fabricated with the digital impression technique had lower marginal misfits than those of the conventional impression technique. The marginal misfit values in that study were lower than the present study. This difference in the results may be due to the fact that the intraoral scanner, restoration material, and restoration type used in this study are different from the current study.

Haddadi et al. ${ }^{20}$ compared lithium disilicate crowns fabricated with digital and conventional impression techniques and reported that the restorations fabricated with the digital impression technique had lower marginal misfits than those of the conventional impression technique. The marginal adaptation data of the specimens acquired by the digital measurement technique were found to be similar with the present study. It can be thought that this similarity is due to the fact that the same digital scanner was used in both studies.

In another study using digitized version of the impression replica technique (dual scan technique), the adaptation of single crown fixed dental prostheses was evaluated. In the study, presintered zirconia, hot isostatic pressed yttriatetragonal zirconia polycrystalline ceramic, lithium disilicate reinforced glass ceramic, milled cobalt-chromium, and lasersintered cobalt-chromium crowns were used. For the control group, the single-unit frameworks were produced with the lost wax metal casting technique with cobalt-chromium by using conventional impression techniques. According to the study results, the researchers reported that laser sintered cobalt-chromium crowns fabricated with the digital impressions technique with the help of Trios intraoral scanner showed significantly better marginal fit than all other digital technique groups and the control group using the conventional technique. ${ }^{8}$ Similarly, in the present study, the measured marginal fit values of the restorations produced with conventional impression was found to be greater than those produced by the digital impression. On the other hand, there was no significant difference in the marginal fit between the digital measurement methods $(P>.05)$.

Keul et al. ${ }^{29}$ evaluated the adaptation of four-unit milled base metal alloy and zirconia frameworks fabricated with the digital impression technique and conventional impression technique. The study results showed that milled base metal alloys fabricated with the digital impression technique showed significantly better marginal adaptation than those metal alloys fabricated with the conventional technique, and this finding supports the current study.

$\mathrm{Su}$ and $\mathrm{Sun}^{18}$ compared the marginal and internal fit of 3-unit zirconia frameworks fabricated with either a conventional or digital impression technique. They reported that the zirconia frameworks fabricated with digital impression systems had better marginal adaptation than those of conventional impression. The results for marginal adaptation were in accordance with the present study. It can be thought that the similar results are due to the fact that the same intraoral scanner and the impression material were used in both studies. 
In this study, after the different impression methods, the compatibility of the frameworks produced with CAD/CAM supported LS technology was examined. LS technologies have overcome many of the disadvantages of the conventional casting. However, this technology has variables that can influence the results of the manufacturing process, such as scanning protocols, software design, and material processing. For this reason, inconsistencies may be seen among the results of studies that test the marginal misfits of CAD/ CAM supported frameworks. ${ }^{31}$ On the other hand, some authors have reported that molar abutments in digitally fabricated frameworks have greater misfits than premolar abutments in the same specimen tested. The authors associated these findings with differences in abutment size and reported that molar teeth may exhibit greater misfits due to their larger surface area..$^{32,37,38}$ In multi-unit frameworks, although the average marginal misfit values of the abutments are within acceptable limits relative to the clinical marginal misfit threshold values reported in the literature, this is not always sufficient for the clinical acceptability of the restoration. Because, when each abutment in the framework is evaluated separately, the marginal misfit values determined may be outside these threshold value.

In multi unit restorations, if the marginal accordance of one of the abutments is insufficient, this causes the final restoration to fail. ${ }^{35}$ The secondary purpose of this study was to evaluate the marginal misfit of each abutment separately. In the present study, when the marginal compatibility of each abutment tooth was examined, it was found that there was no difference in the marginal misfit between canine or premolar abutments in the same framework. Thus, the second null hypothesis of this study was accepted. Similar to the present study, in another study using premolar and molar teeth as the abutment, the marginal misfits of LS 3-unit frameworks were evaluated and numerical differences were found about the marginal misfits between the abutments. However, these differences were not statistically significant. ${ }^{31}$

Colpani et al..$^{39}$ reported that a marginal discrepancy can be considered acceptable when it is visually indistinct or cannot be identified with a dental explorer. Up to this time, no consensus exists on clinically acceptable marginal misfit values. McLean and von Fraunhofer reported that restorations with marginal misfits less than $120 \mu \mathrm{m}$ were clinically acceptable. ${ }^{25}$ Other studies reported that misfit values below $100 \mu \mathrm{m}$ were acceptable. ${ }^{26,27}$ In the present study, the marginal adaptation of LS FDPs in both the digital and conventional impression groups were clinically acceptable. ${ }^{25}$ Larger marginal misfit values were obtained in Group $\mathrm{Ci}$, in both canine and premolar teeth. The better marginal adaptation of the digital impression groups may be explained by error caused during the conventional impression making process and by the result of the multiple production steps or impression procedures in group $\mathrm{Ci}$. The casts might be deformed during the polymerization or adaptation of the restorations. A recent study reported that Type IV dental stone had a linear expansion of between $0.06 \%$ and $0.5 \%{ }^{40}$
Corso et al. ${ }^{41}$ reported that PVS impression material contracted by $17 \mu \mathrm{m}$ in the horizontal line and $2 \mu \mathrm{m}$ in the vertical line after storage at room temperature. The results obtained in these studies could explain the marginal discrepancy differences between the digital and conventional impression groups in present study.

There has been an increase in the number of studies on the marginal fit of restorations produced by laser-sintered technology in dentistry. In most of these studies, although researchers have evaluated different frameworks and manufacturing techniques, superior marginal adaptation of $\mathrm{Co}-\mathrm{Cr}$ specimens produced by laser-sinter is thought to be from preventing the distortion of casting methods. ${ }^{8}$

In previous studies, several materials such as dentoform teeth, ${ }^{14,31}$ cobalt-chromium, ${ }^{2}$ and zirconia ${ }^{42}$ have been used for master dies. In this study, brass dies were used as the master dies because of their high deformation resistance. ${ }^{43}$

This standardized study evaluated the marginal misfit of three-unit LS frameworks fabricated with different impression techniques. All the frameworks were fabricated with the same software and design, with the same anatomy, and with the same laser sintering machine software. The single variable was the impression technique. All conventional and digital impression making procedures and the marginal discrepancy measurements were performed by the same operator (H.K.). The main drawback of LS crown fabrication is the need for trained technicians to evaluate subgingival margins. ${ }^{25}$ For this reason, in this study, all set-up and production procedures of the frameworks were performed by the same trained technician using the same settings and the same equipment. ${ }^{8}$

Several techniques for measuring marginal misfit values have been reported, including the silicone replica technique, ${ }^{30} 3$-dimensional measurements, ${ }^{14}$ the cross-sectional technique, ${ }^{17}$ direct techniques with cone beam computed tomography (CBCT) evaluation, ${ }^{4}$ and the silicone weight technique. ${ }^{25}$ The cross-sectional technique damages the frameworks and master dies, and both CBCT and 3-dimensional measurement techniques require advanced technology. ${ }^{9}$ In this study, a direct view method was used to measure the marginal misfit of the frameworks ${ }^{10}$ because it was straightforward, inexpensive, and reproducible, and did not damage the frameworks or dies.

This study, which evaluated the marginal misfit of frameworks fabricated with different impression techniques, has some limitations. The effect of the artificial aging process, veneering ceramic, and intraoral conditions on the marginal misfit were not evaluated. This study should be developed by examining the effect of artificial aging process, veneering ceramic material and veneering process on marginal adaptation. In addition, it is important to examine the effect of intraoral conditions on marginal adaptation and to support present study with clinical studies. In this study, only the frameworks produced by LS fabrication technique were examined. Further research is necessary to validate the present results and to compare LS fabrication technique with various other types of fabrication techniques. 


\section{CONCLUSION}

Within the limitations of this in vitro study, the following conclusions were obtained. In this study, it has been found that, the frameworks fabricated with digital impression techniques had achieved a better marginal fit compared to those fabricated with conventional impression technique. There was no significant difference between the intraoral scanners of the digital systems used in this study. Regardless of the impression technique used, the marginal misfits of the frameworks in all conventional or digital impression groups were clinically acceptable. No significant difference was found between the canine and premolar abutment teeth in terms of marginal misfits in the same framework design.

\section{ORCID}

Hasan Kocaağaoğlu bttps://orcid.org/0000-0003-3072-7211

Haydar Albayrak https://orcid.org/0000-0002-2833-1317

Sezgi Cinel Sahin https://orcid.org/0000-0001-7623-782X

Ayşegül Güleryüz Gürbulak https://orcid.org/0000-0002-90264901

\section{REFERENCES}

1. Walton TR. The up to 25 -year survival and clinical performance of 2,340 high gold-based metal-ceramic single crowns. Int J Prosthodont 2013;26:151-60.

2. An S, Kim S, Choi H, Lee JH, Moon HS. Evaluating the marginal fit of zirconia copings with digital impressions with an intraoral digital scanner. J Prosthet Dent 2014;112:1171-5.

3. Vennerstrom M, Fakhary M, Von Steyern PV. The fit of crowns produced using digital impression systems. Swed Dent J 2014; 38:101-10.

4. Şeker E, Ozcelik TB, Rathi N, Yilmaz B. Evaluation of marginal fit of $\mathrm{CAD} / \mathrm{CAM}$ restorations fabricated through cone beam computerized tomography and laboratory scanner data. J Prosthet Dent 2016;115:47-51.

5. Borba M, Cesar PF, Griggs JA, Della Bona Á. Adaptation of all-ceramic fixed partial dentures. Dent Mater 2011;27:111926.

6. Punj A, Bompolaki D, Garaicoa J. Dental Impression Materials and Techniques. Dent Clin North Am 2017;61:779-96.

7. Euán R, Figueras-Álvarez O, Cabratosa-Termes J, OliverParra R. Marginal adaptation of zirconium dioxide copings: influence of the CAD/CAM system and the finish line design. J Prosthet Dent 2014;112:155-62.

8. Dahl BE, Dahl JE, Rønold HJ. Digital evaluation of marginal and internal fit of single-crown fixed dental prostheses. Eur J Oral Sci 2018;126:512-7.

9. Praça L, Pekamc FC, Regod RO, Radermacherc K, Wolfarta S, Marottia J. Accuracy of single crowns fabricated from ultrasound digital impressions. Dent Mater 2018;34:e280-8.

10. Anadioti E, Aquilino SA, Gratton DG, Holloway JA, Denry IL, Thomas GW, Qian F. Internal fit of pressed and computeraided design/computer-aided manufacturing ceramic crowns made from digital and conventional impressions. J Prosthet
Dent 2015;113:304-9.

11. Ahlholm P, Sipilä K, Vallittu P, Jakonen M, Kotiranta U. Digital versus conventional impressions in fixed prosthodontics: A review. J Prosthodont 2018;27:35-41.

12. Gabor AG, Zaharia C, Stan AT, Gavrilovici AM, Negrutiu ML, Sinescu C. Digital Dentistry-Digital Impression and CAD/CAM system applications. J Interdisciplinary Med 2017;2:54-7.

13. $\mathrm{Ng}$ J, Ruse D, Wyatt C. A comparison of the marginal fit of crowns fabricated with digital and conventional methods. J Prosthet Dent 2014;112:555-60.

14. Anadioti E, Aquilino SA, Gratton DG, Holloway JA, Denry I, Thomas GW, Qian F. 3D and 2D marginal fit of pressed and CAD/CAM lithium disilicate crowns made from digital and conventional impressions. J Prosthodont 2014;23:610-7.

15. Abdel-Azim T, Rogers K, Elathamna E, Zandinejad A, Metz M, Morton D. Comparison of the marginal fit of lithium disilicate crowns fabricated with CAD/CAM technology by using conventional impressions and two intraoral digital scanners. J Prosthet Dent 2015;114:554-9.

16. Schaefer O, Decker M, Wittstock F, Kuepper H, Guentsch A. Impact of digital impression techniques on the adaption of ceramic partial crowns in vitro. J Dent 2014;42:677-83.

17. Vandeweghe S, Vervack V, Dierens M, De Bruyn H. Accuracy of digital impressions of multiple dental implants: an in vitro study. Clin Oral Implants Res 2017;28:648-53.

18. Su TS, Sun J. Comparison of marginal and internal fit of 3 -unit ceramic fixed dental prostheses made with either a conventional or digital impression. J Prosthet Dent 2016;116:3627.

19. Renne W, Wolf B, Kessler R, McPherson K, Mennito AS. Evaluation of the marginal fit of CAD/CAM crowns fabricated using two different chairside CAD/CAM systems on preparations of varying quality. J Esthet Restor Dent 2015;27:194202.

20. Haddadi Y, Bahrami G, Isidor F. Accuracy of crowns based on digital intraoral scanning compared to conventional impression-a split-mouth randomised clinical study. Clin Oral Investig 2019;23:4043-50.

21. Takeuchi Y, Koizumi H, Furuchi M, Sato Y, Ohkubo C, Matsumura H. Use of digital impression systems with intraoral scanners for fabricating restorations and fixed dental prostheses. J Oral Sci 2018;60:1-7.

22. Nesse H, Ulstein DM, Vaage MM, Øilo M. Internal and marginal fit of cobalt-chromium fixed dental prostheses fabricated with 3 different techniques. J Prosthet Dent 2015;114:68692.

23. Dikbas I, Tanalp J, Tomruk CO, Koksal T. Evaluation of reasons for extraction of crowned teeth: a prospective study at a university clinic. Acta Odontol Scand 2013;71:848-56.

24. McLean JW, von Fraunhofer JA. The estimation of cement film thickness by an in vivo technique. Br Dent J 1971;131:10711.

25. Ucar Y, Akova T, Akyil MS, Brantley WA. Internal fit evaluation of crowns prepared using a new dental crown fabrication technique: laser-sintered Co-Cr crowns. J Prosthet Dent 2009; 102:253-9. 
26. Sakrana AA. In vitro evaluation of the marginal and internal discrepancies of different esthetic restorations. J Appl Oral Sci 2013;21:575-80.

27. Ortega R, Gonzalo E, Gomez-Polo M, Suárez MJ. Marginal and internal discrepancies of posterior zirconia-based crowns fabricated with three different CAD/CAM systems versus metal-ceramic. Int J Prosthodont 2015;28:509-11.

28. Zoellner A, Brägger U, Fellmann V, Gaengler P. Correlation between clinical scoring of secondary caries at crown margins and histologically assessed extent of the lesions. Int J Prosthodont 2000;13:453-9.

29. Keul C, Stawarczyk B, Erdelt KJ, Beuer F, Edelhoff D, Güth JF. Fit of 4-unit FDPs made of zirconia and CoCr-alloy after chairside and labside digitalization-a laboratory study. Dent Mater 2014;30:400-7.

30. Kocaağaoğlu H, Kilınç Hİ, Albayrak H, Kara M. In vitro evaluation of marginal, axial, and occlusal discrepancies in metal ceramic restorations produced with new technologies. J Prosthet Dent 2016;116:368-74.

31. Afify A, Haney S, Verrett R, Mansueto M, Cray J, Johnson R. Marginal discrepancy of noble metal-ceramic fixed dental prosthesis frameworks fabricated by conventional and digital technologies. J Prosthet Dent 2018;119:307.e1-307.e7.

32. Svanborg P, Skjerven H, Carlsson P, Eliasson A, Karlsson S, Ortorp A. Marginal and internal fit of cobalt-chromium fixed dental prostheses generated from digital and conventional impressions. Int J Dent 2014;2014:534382.

33. Eroğlu Z, Gurbulak AG. Fatigue behavior of zirconia-ceramic, galvano-ceramic, and porcelain-fused-to-metal fixed partial dentures. J Prosthodont 2013;22:516-22.

34. EOS. Material Data Sheet EOS CobaltChrome SP2 material for EOSINT M 270. No., 2009. (https://www.eos.info/material-m).

35. Memarian M, Sadighpour L, Nosratpour R, Fard MJK. Marginal adaptation and internal fit of posterior 3-unit zirconia FPDs fabricated with different CAD/CAM systems. Eur J Prosthodont Restor Dent 2017;25:79-85.

36. Dureja I, Yadav B, Malhotra P, Dabas N, Bhargava A, Pahwa R. A comparative evaluation of vertical marginal fit of provisional crowns fabricated by computer-aided design/computer-aided manufacturing technique and direct (intraoral technique) and flexural strength of the materials: An in vitro study. J Indian Prosthodont Soc 2018;18:314-20.

37. Örtorp A1, Jönsson D, Mouhsen A, Vult von Steyern P. The fit of cobalt-chromium three-unit fixed dental prostheses fabricated with four different techniques: a comparative in vitro study. Dent Mater 2011;27:356-63.

38. Boitelle P, Mawussi B, Tapie L, Fromentin O. A systematic review of CAD/CAM fit restoration evaluations. J Oral Rehabil 2014;41:853-74.

39. Colpani JT, Borba M, Della Bona A. Evaluation of marginal and internal fit of ceramic crown copings. Dent Mater 2013; 29:17480.

40. Kenyon BJ, Hagge MS, Leknius C, Daniels WC, Weed ST. Dimensional accuracy of 7 die materials. J Prosthodont 2005;14: 25-31.

41. Corso M, Abanomy A, Di Canzio J, Zurakowski D, Morgano
SM. The effect of temperature changes on the dimensional stability of polyvinyl siloxane and polyether impression materials. J Prosthet Dent 1998;79:626-31.

42. Xu D, Xiang N, Wei B. The marginal fit of selective laser melting-fabricated metal crowns: an in vitro study. J Prosthet Dent. 2014;112:1437-40.

43. Wankhade S, Sanghavi K, Rajguru V, Lokade J. A comparative evaluation of six commonly used types of die materials for the property of abrasion resistance, at two time intervals: an in vitro study. Int J Prosthodont Restor Dent 2013;3:1-6. 